\title{
Monitoring Damage Accumulation in Ceramic Matrix Composites Using Electrical Resistivity
}

\author{
Craig E. Smith ${ }^{1}$, Gregory N. Morscher ${ }^{2}$, Z.H. Xia ${ }^{1}$ \\ ${ }^{1}$ Department of Mechanical Engineering, University of Akron, Akron, OH 44325 \\ ${ }^{2}$ Ohio Aerospace Institute, Ceramics Branch, NASA Glenn Research Center MS 106-5, \\ Cleveland, $\mathrm{OH} 44224$
}

\begin{abstract}
The electric resistance of woven $\mathrm{SiC}$ fiber reinforced $\mathrm{SiC}$ matrix composites were measured under tensile loading conditions. The results show that the electrical resistance is closely related to damage and that real-time information about the damage state can be obtained through monitoring of the resistance. Such self-sensing capability provides the possibility of on-board/in-situ damage detection and accurate life prediction for hightemperature ceramic matrix composites.

Woven silicon carbide fiber-reinforced silicon carbide $(\mathrm{SiC} / \mathrm{SiC})$ ceramic matrix composites (CMC) possess unique properties such as high thermal conductivity, excellent creep resistance, improved toughness, and good environmental stability (oxidation resistance), making them particularly suitable for hot structure applications. In specific, CMCs could be applied to hot section components of gas turbines [1], aerojet engines [2], thermal protection systems [3], and hot control surfaces [4]. The benefits of implementing these materials include reduced cooling air requirements, lower weight, simpler component design, longer service life, and higher thrust [5]. It has been identified in NASA High Speed Research (HSR) program that the $\mathrm{SiC} / \mathrm{SiC} \mathrm{CMC}$ has the most promise for high temperature, high oxidation applications [6].

One of the critical issues in the successful application of CMCs is on-board or insitu assessment of the damage state and an accurate prediction of the remaining service life of a particular component. This is of great concern, since most CMC components envisioned for aerospace applications will be exposed to harsh environments and play a key role in the vehicle's safety. On-line health monitoring can enable prediction of remaining life; thus resulting in improved safety and reliability of structural components. Monitoring can also allow for appropriate corrections to be made in real time, therefore leading to the prevention of catastrophic failures. Most conventional nondestructive evaluation (NDE) techniques such as ultrasonic C-scan, x-ray, thermography, and eddy current are limited since they require structural components of complex geometry to be taken out of service for a substantial length of time for post-damage inspection and assessment. Furthermore, the typical NDE techniques are useful for identifying large interlaminar flaws, but insensitive to CMC materials flaws developed perpendicular to the surface under tensile creep conditions. There are techniques such as piezoelectric sensor $[7,8]$, and optical fiber $[9,10]$ that could be used for on-line health monitoring of $\mathrm{CMC}$ structures. However, these systems involve attaching an external sensor or putting special fibers in $\mathrm{CMC}$ composites, which would be problematic at high temperature applications.
\end{abstract}


Most composite materials are multifunctional materials in which the damage is coupled with the material electrical resistance, providing the possibility of real-time information about the damage state through monitoring of resistance. Electrical resistance has been shown to be a sensitive measure of internal damage in a number of composite systems such as carbon fiber reinforced polymer (CFRP), silicon carbide-fiber reinforced glasses and 2D carbon fiber-reinforced silicon carbide [11-13]. In such composites, the fibers are the conductive material, while the matrix acts as an insulator by comparison. This allows for detection mainly of fiber breakage by measuring the resistance change of the materials. In contrast, for the $\mathrm{SiC} / \mathrm{SiC}$ composites, the resistivity of the matrix is on the same order of magnitude as that of the fibers. The resistance may be sensitive to matrix cracks which are far more important to mechanical properties of CMC materials. However, little study on $\mathrm{SiC} / \mathrm{SiC}$ composites has been reported to our knowledge. In this letter, we demonstrate that the electrical resistance closely correlates with matrix cracking in the $\mathrm{SiC} / \mathrm{SiC}$ composites, and that real-time information about the damage state can be obtained through monitoring of the resistance. This work thus provides a self-sensing approach for on-board/in-situ damage detection and life prediction of high-temperature CMC structures.

The materials used in this study are Sylramic-iBN, Hi Nicalon, and Hi Nicalon type $S$ fibers with CVI matrices and boron nitride interfaces. The fibers are woven in a 2D, five harness satin, with 8 plies. Half the fibers are in the loading direction and half are perpendicular to the load. Table 1 lists the specimen properties. With the exception of fiber type, the main difference between the specimens is the fiber volume fraction, which ranges from 0.202 for the Hi-Nic to 0.310 for the Syl-iBN. The resistivity of the three materials before loading is also listed in Table 1. Of the three materials, woven Hi-Nic fiber composites have the highest resistivity $(27 \Omega-\mathrm{cm})$, while Syl-iBN fiber composites are the lowest, with a resistivity of $10.36 \Omega-\mathrm{cm}$. Samples with Hi-NicS fibers were found to have a resistivity of $10.45 \Omega-\mathrm{cm}$, which is close to the Syl-iBN.

Unload-reload tensile hysteresis tests were performed on the $\mathrm{SiC} / \mathrm{SiC} \mathrm{CMC}$ specimens shown schematically in Figure 1. $150 \mathrm{~mm}$ long specimens with a contoured gage section were tested on an Instron universal testing machine. Glass fiber reinforced epoxy tabs were adhered to the grip regions and the samples were gripped with rigidly mounted hydraulically actuated wedge grips. A capacitance strain gage with a range of $1 \%$ over $25 \mathrm{~mm}$ was used to measure the extension of the gage section. Loading and unloading was performed at a rate of $4 \mathrm{kN} / \mathrm{min}$. Resistance of these composites was measured by the four point probe method. In the measurement, a constant current is applied through the material between two outer probes. The voltage is measured across the two inner probes to determine the resistance of the material. The advantage of this procedure is that it minimizes the effect of surface resistance on the measurements, since the current through the inner probes should be near zero. For probe attachment, a thin strip of conductive silver paste was applied around the specimen perimeter and thin wires were then wrapped around the surface of the silver and taped in place. The outer probes were spaced $45 \mathrm{~mm}$ apart and the inner probes were spaced $15 \mathrm{~mm}$ apart. An Agilent $34420 \mathrm{~A}$ voltmeter was used to directly measure the four point resistance.

In addition to four point resistance measurements, modal acoustic emission was monitored throughout the test by $50 \mathrm{kHz}$ to $2.0 \mathrm{MHz}$ sensors placed just inside the grip area. The acoustic sensors were clamped to the specimen surface and vacuum grease was 
used as a couplant between the two. The waveforms were recorded by an 8 channel fracture wave detector produced by Digital Wave Corp. Software from the same company was used to filter the acoustic events and analyze those which only occurred within the gage section $[14,15]$.

Figures $2 \mathrm{a}-\mathrm{c}$ are plots of the applied stress, acoustic energy, and resistance change of the samples as they were tensile tested in hysteresis loops. For each stress loop, the resistance increases at first and then reduces, in response to the stress change in the loop. It is interesting that all specimens are characterized by a resistance curve that closely follows the slope of the acoustic curve for the first few loading cycles and then increases at a greater rate than $\mathrm{AE}$ for higher stresses close to failure. This characteristic indicates that the first portion of the resistance curve is caused by matrix crack formation, while the higher stress portion is a result of phenomena that do not cause acoustic emission, such as crack opening and fiber strain. All CVI samples are well behaved in the sense that the resistivity curve for the unloading of one cycle and loading of the subsequent cycle is symmetric. In other words, as the specimen is reloaded, resistivity returns to the previous maximum and then increases at a greater rate once acoustic events commence. Matrix cracks that are closed or partially closed upon unloading are reopened as stress increases, followed by the formation of new cracks once the stress level exceeds the previous maximum. This repeatable pattern indicates that the number and severity of matrix cracks, along with accurate estimates of remaining life, can be determined at any point in the service life of a part.

Another interesting characteristic of the resistance curves is the residual resistance, as shown in Figure 2. Upon unloading, resistivity drops below the peak value, but never fully returns to the level it was at prior to loading. There is permanent change in resistivity upon each loading cycle. Figure 3 shows the stress, along with maximum and residual resistance changes in each loop as a function of strain. Both maximum and residual resistances increase with increasing strain. The value of the residual resistance depends on the maximum strain during past loading loops, much like those observed in $\mathrm{SiC} /$ polymer and CFRP composites [16, 17]. Obviously, the irreversible resistance is attributed to the matrix cracks that are formed during loading cycle. This behavior indicates that the damage and maximum loading history could be "recorded" by the residual resistance. Such features could be valuable for a host of other loading and damage conditions, as noted by prior workers [16-21]. For instance, after a mission is complete and the structure is unloaded, the damage contribution to the resistance remains. The measured response is thus that of the largest strain experienced by the component in the vicinity of the measurement. Hence, the change in residual resistance can be used as an inspection technique.

The microstructures of the $\mathrm{SiC} / \mathrm{SiC}$ composites which were subjected to unload/reload tensile tests were then examined by optical microscope and are shown in Figure 4. Generally, the extensive transverse cracks are generated during the test and the damage accumulation is closely related to applied stress. The crack densities of the tested specimens were measured and are listed in Table 1. All are between 2.4 and 2.8 cracks per $\mathrm{mm}$, with cracks forming through the entire thickness. As stress on the samples is increased, the number of matrix cracks increases, leading to the increases in resistivity and acoustic energy. The acoustic energy released during loading has been shown to be directly proportional with the number of matrix cracks in $\mathrm{SiC} / \mathrm{SiC} \mathrm{CMC}$ 
[15]. Since the resistance is closely related to the acoustic energy it is expected that a quantitative correlation between the resistance change and crack density could be established for $\mathrm{SiC} / \mathrm{SiC}$ composites.

To make the self-sensing method predictive, theoretical relationship between mechanical damage and resistance change is necessary. The strain behavior of the composite with matrix cracks has been modeled with micromechanics of bridged matrix flaws [22]. From the micromechanics analysis, matrix crack density $\rho$ is related to the interfacial shear stress $\tau$, the residual stress $\sigma_{\text {th }}$, and stress-strain $(\sigma-\varepsilon)$ curves by $\rho=2 \tau E_{f}\left(\varepsilon-\sigma / E_{c}\right) /\left[r \alpha^{2}\left(\sigma+\sigma_{t h}\right)^{2}\right]$, where $r$ is the fiber radius, $\alpha=(1-f) E_{m} / f E_{c}, f$ is the fiber volume friction, and $E$ is elastic modulus, subscripts $c, f$, and $m$ refer to composite, fiber, and matrix. Since $\tau$ is an unknown parameter, the above equation was calibrated by using the measured matrix crack density in Table 1 . On the other hand, the resistance change $\Delta \mathrm{R} / \mathrm{R}_{0}$ can be expressed approximately as $\Delta R / R_{0}=A \varepsilon+B \rho^{n}$, where $A$ is the piezoelectric constant of the composites, $B$ and $n$ are the constants related to matrix cracking. Combing the above equations gives a relation between the resistance change $\Delta R / R_{0}$ and the strain $\varepsilon$. The combined equation was used to fit the experimental results for the woven Syl-iBN/CVI composite (Figure 3). At small strain the equation fits the experimental very well by using parameters of $A=3000, B=0.15 \mathrm{~mm}^{-5}$ and $n=5$. However, when the strain is large ( $\mathrm{AE}$ energy reaches the plateau, i.e. matrix cracks saturate) the predictions deviate from the experimental data. Since the above predictions are based on the matrix cracking analysis only, it is suggested that other mechanisms, such as pullout and fiber breakage, dominate the resistance change at higher applied stress. Similar results were obtained for two other materials. More detailed analysis is therefore needed and the results will be reported separately.

Most of the past and current research effort on damage detection utilizing the electric resistance has focused on polymer composite materials and using fiber conductivity. Although such an approach has been promising, so far it has been less effective in detecting matrix damage such as matrix cracking and delamination. The results presented here demonstrate that self-sensing using matrix conductivity can effectively detect matrix damage which is critical to the life of high-temperature CMC structures. Specifically, we have shown that the resistance change in $\mathrm{SiC} / \mathrm{SiC}$ composite systems is very sensitive to the matrix cracking and closely related to the damage evolution. We also show that it is possible to detect the largest inadvertent overloads in $\mathrm{CMC}$ materials by measuring the residual resistance after a mission is completed. The experimental results here thus provide the basis for an online health monitoring strategy and non-destructive evaluation method for high-temperature $\mathrm{CMC}$ materials.

\section{Acknowledgements}

We would like to thank the NASA Glenn Research Center ARMD Hypersonics program for the support of the graduate student research program under contract NNX07AN56H and the Glenn Research Center Ceramics branch for use of their research facilities.

\section{References}

[1] G. S. Corman, A. J. Dean, S. Brabetz, M. K. Brun, K. L. Luthra, L. Tognarelli, M. Pecchioli, Journal of Engineering for Gas Turbines and Power 2002; 124: 459-464 
[2] R.R. Naslain, International Journal of Applied Ceramic Technology 2005; 2:75-84

[3] W. Krenkel, F. Berndt, Materials Science and Engineering A, 2005; 412:177-181

[4] P. G. Valentine, H. K. Rivers; V. L. Chen, X-37 C-SiC CMC Control Surface Components Development Status of the NASA Boeing USAF Orbital Vehicle and Related Efforts, Langley Research Center, Marshall Space Flight Center, (2003).

[5] J.A. DiCarlo, H-m. Yun, G.N. Morscher, R.T. Bhatt, SiC/SiC composites for $1200^{\circ} \mathrm{C}$ and Above. In: Narottam P Bansal, Spinger editors. Handbook of Ceramic Composites, 2005. p.78

[6] Brewer, D., Mater. Sci. Eng. 1999; A261:284-291

[7] A. Raghavan and C. E. S. Cesnik, The Shock and Vibration Digest 2007; 39:91-114

[8] V. Giurgiutiu and A. Cuc, The Shock and Vibration Digest 2005; 37: 83-105

[9] G. Zhou and L. M. Sim, Smart Mater. Struct. 2002; 11:925-939

[10] M. A. El-Sherif, J. Yuan, NDE technique for ceramic composites using embedded sapphire optical waveguides, Proc. SPIE, 2944, 154-165(1996).

[11] Fankhanel, Muller, Mosler, Siegel, Journal of European Ceramic Society 2001; 21: 649-657

[12] Hui Mei, Laifei Cheng, Materials Letters 2005; 59:3246-3251

[13] Z. H. Xia, T. Okabe, J. B. Park, W. A. Curtin, and N. Takeda, Composites Science and Technology 2003; 63:1411-1422

[14] G.N. Morscher, Comp. Sci. Tech. 1999; 59 : 687-697.

[15] G. N. Morscher, Composites Science and Technology 2004; 64:1311-1319

[16] T. Ogasawara, S. Aizawa, T. Ogawa, T. Ishikawa, Composites Science and Technology 2007; 67:955-962

[17] K. Schulte and C. Baron, Comp. Sci. Tech. 1989; 36:63

[18] K. Schulte and H. Wittich, The Electrical Response of Strained and/or Damaged Polymer Matrix-Composites, Proc. ICCM-10 (1995).

[19] X. Wang and D. D. L. Chung, "Sensing Damage in Carbon Fiber Polymer-matrix Composites during Fatigue by Electrical Resistance Measurements", Proc. SPIE, 3330, $36(1998)$

[20] X. Wang and D. D. L. Chung, Sensors and Actuators 1998; A71:208

[21] J. C.Abry, S. Bochard, A. Chateauminois, M. Salvia, and G. Giraud, Comp. Sci. Tech. 1999; 59:925

[22] W. A. Curtin, B. K. Ahni and N. Takeda, Acta Mater. 1998; 46: 3409 
Table 1. Material properties of the composites examined in this study.

\begin{tabular}{|l|c|c|c||c|c|c|}
\hline Materials & $\begin{array}{c}\text { Fiber } \\
\text { Radius } \\
(\mu \mathrm{m})\end{array}$ & $\begin{array}{c}\text { Fibers } \\
\text { per } \\
\text { Tow }\end{array}$ & $\begin{array}{c}\text { Fiber } \\
\text { Volume } \\
\text { Fraction }\end{array}$ & $\begin{array}{c}\text { Young's } \\
\text { Modulus } \\
(\mathbf{G P a})\end{array}$ & $\begin{array}{c}\text { Nominal } \\
\text { Resistivity } \\
(\mathbf{o h m}-\mathbf{c m})\end{array}$ & $\begin{array}{c}\text { Cracks/mm } \\
\text { after } \\
\text { loading }\end{array}$ \\
\hline Syl-iBN CVI* & 5 & 800 & 0.310 & 205 & 10.36 & 2.7 \\
\hline Hi-NicS CVI** & 6.5 & 500 & 0.247 & 252 & 10.45 & 2.4 \\
\hline Hi-Nic CVI** & 6.75 & 500 & 0.202 & 235 & 27.00 & 2.8 \\
\hline
\end{tabular}

Note: All composites have 8 plies with a BN interphase. ${ }^{*}$ COIC Sylramic + NASA iBN heat treatment; **Nippon Carbon, Tokyo, Japan.

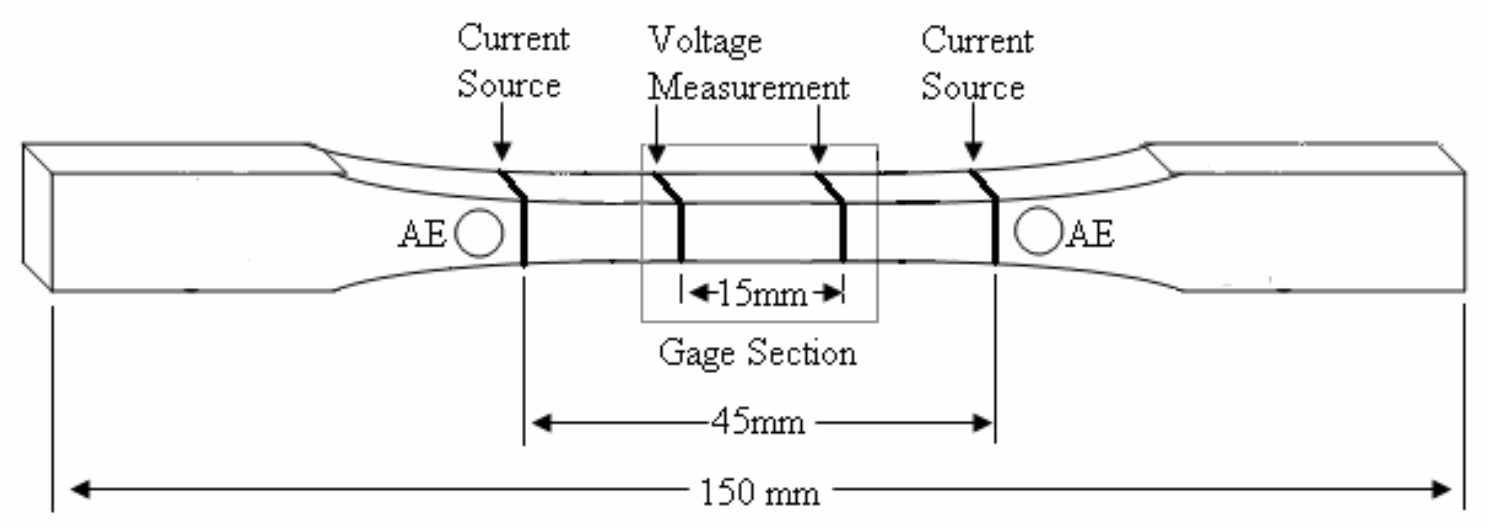

Figure 1. Schematic of tensile test specimen, electrodes, and AE sensor alignment. 


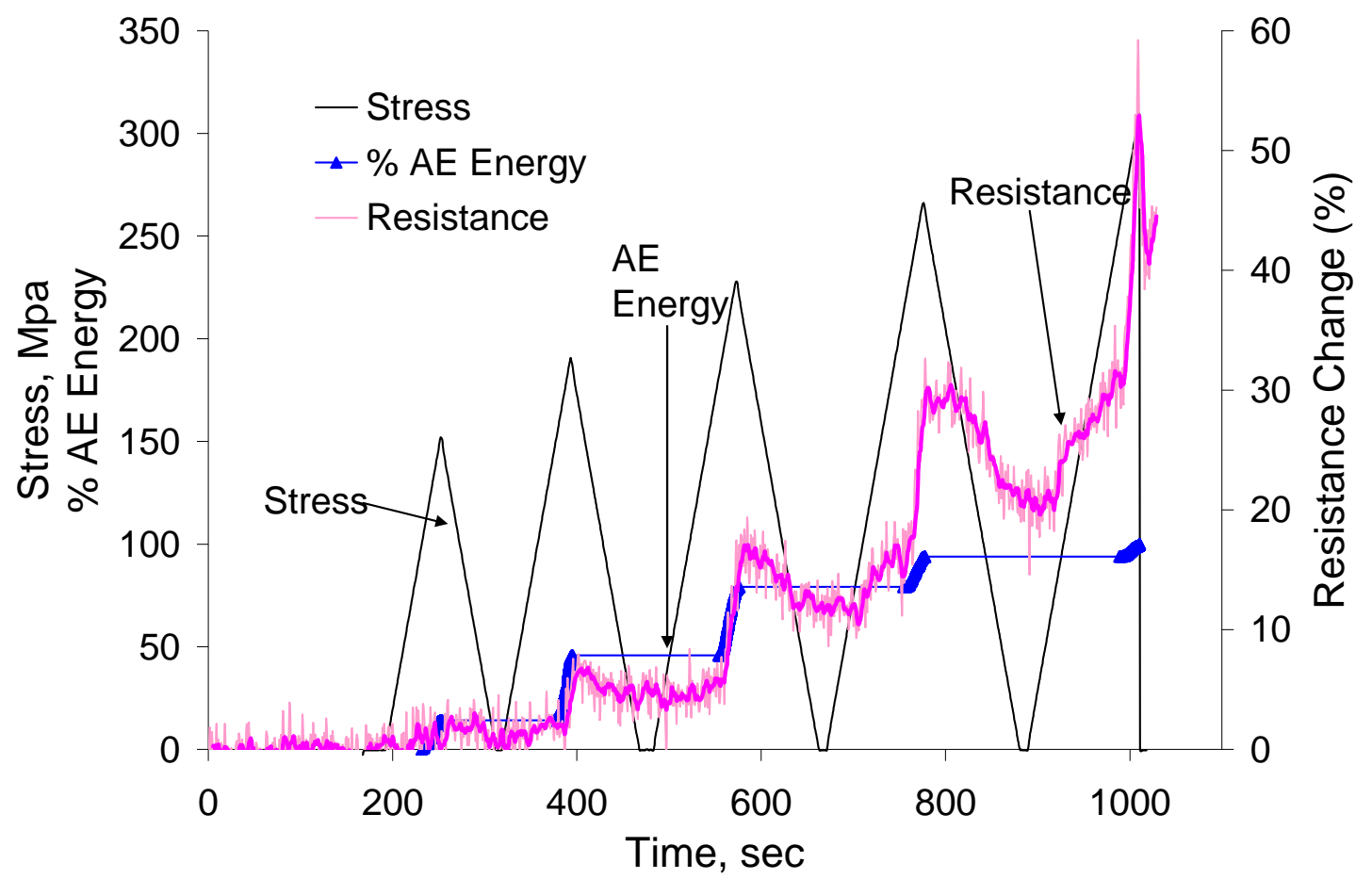

(a)

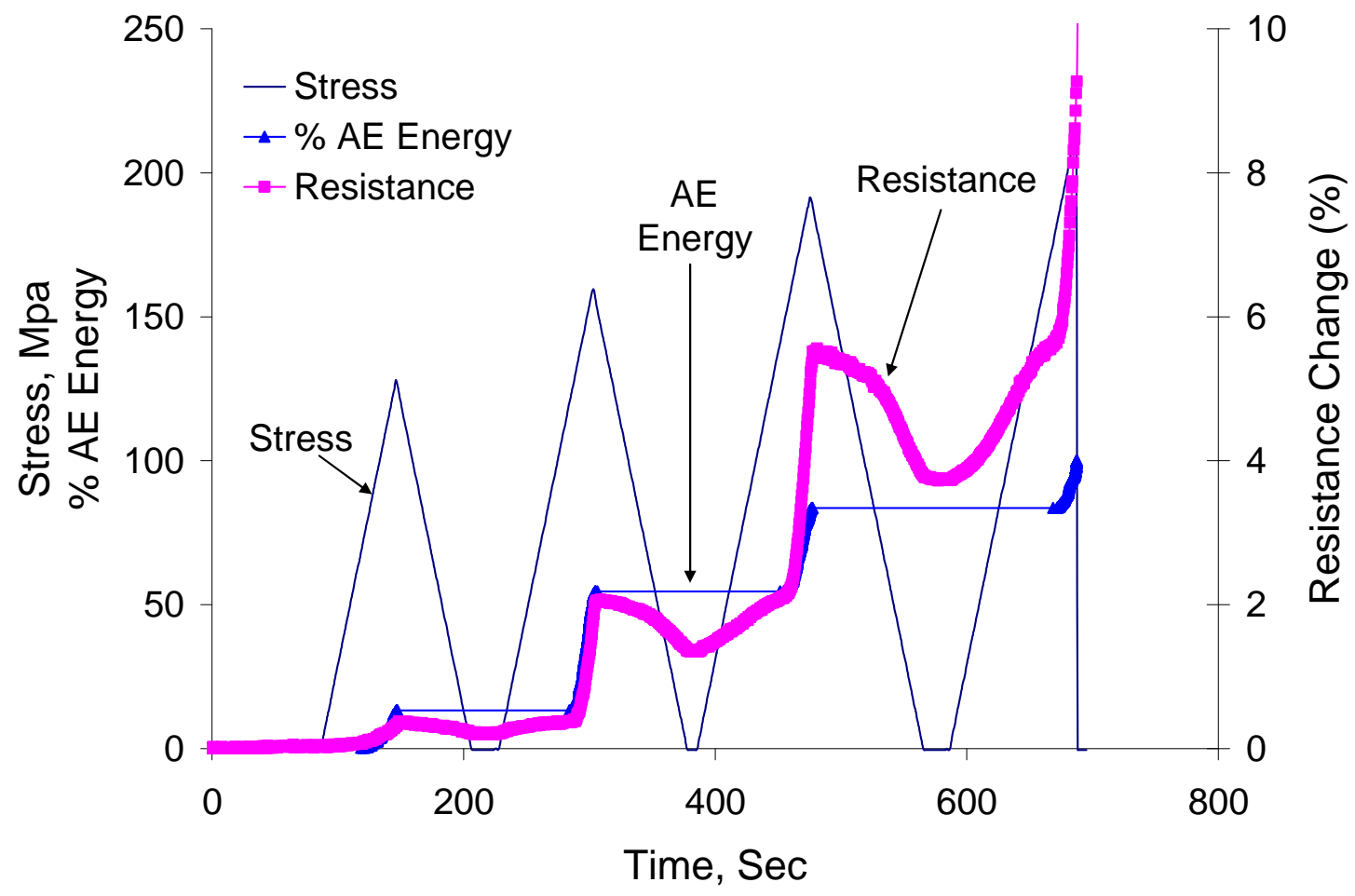

(b) 


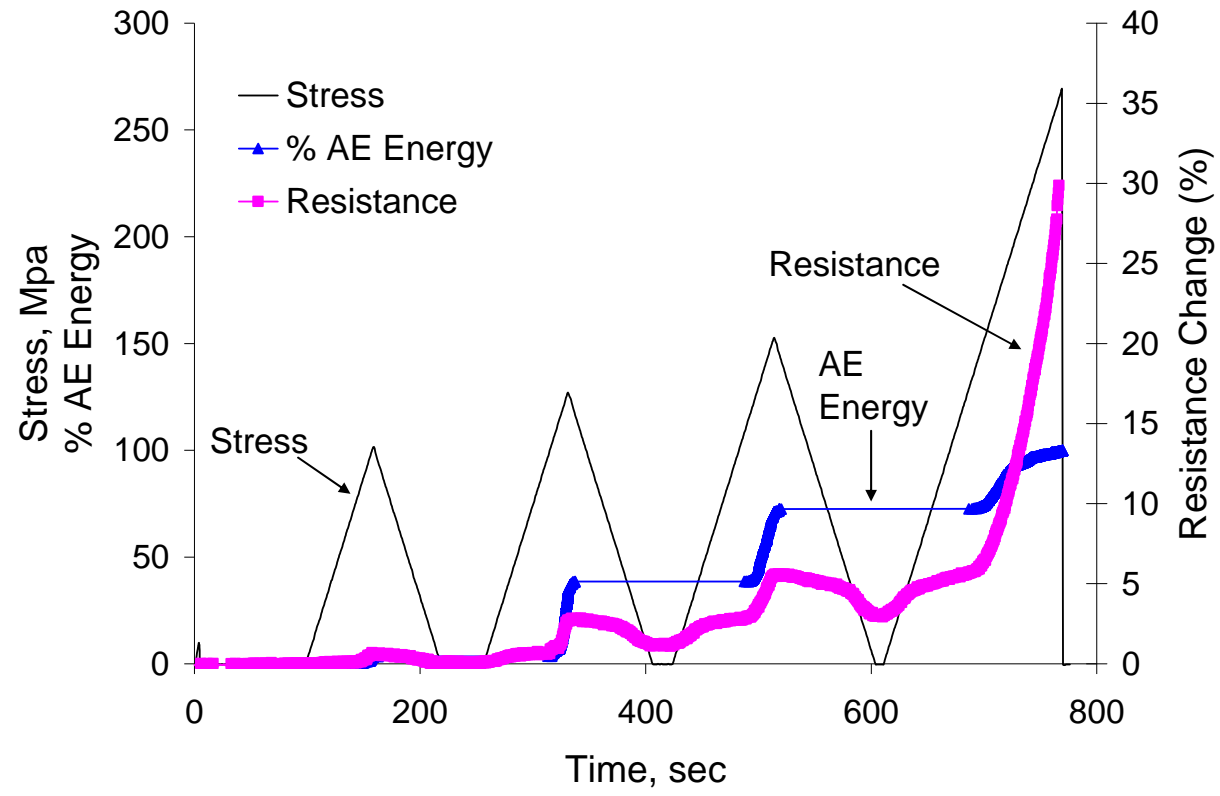

(c)

Figure 2. Stress AE energy and resistance change versus time during unload-reload tensile test to failure for woven (a) CVI/Syl-iBN, (b) CVI/HS and (c) CVI/HN CMC composite. 


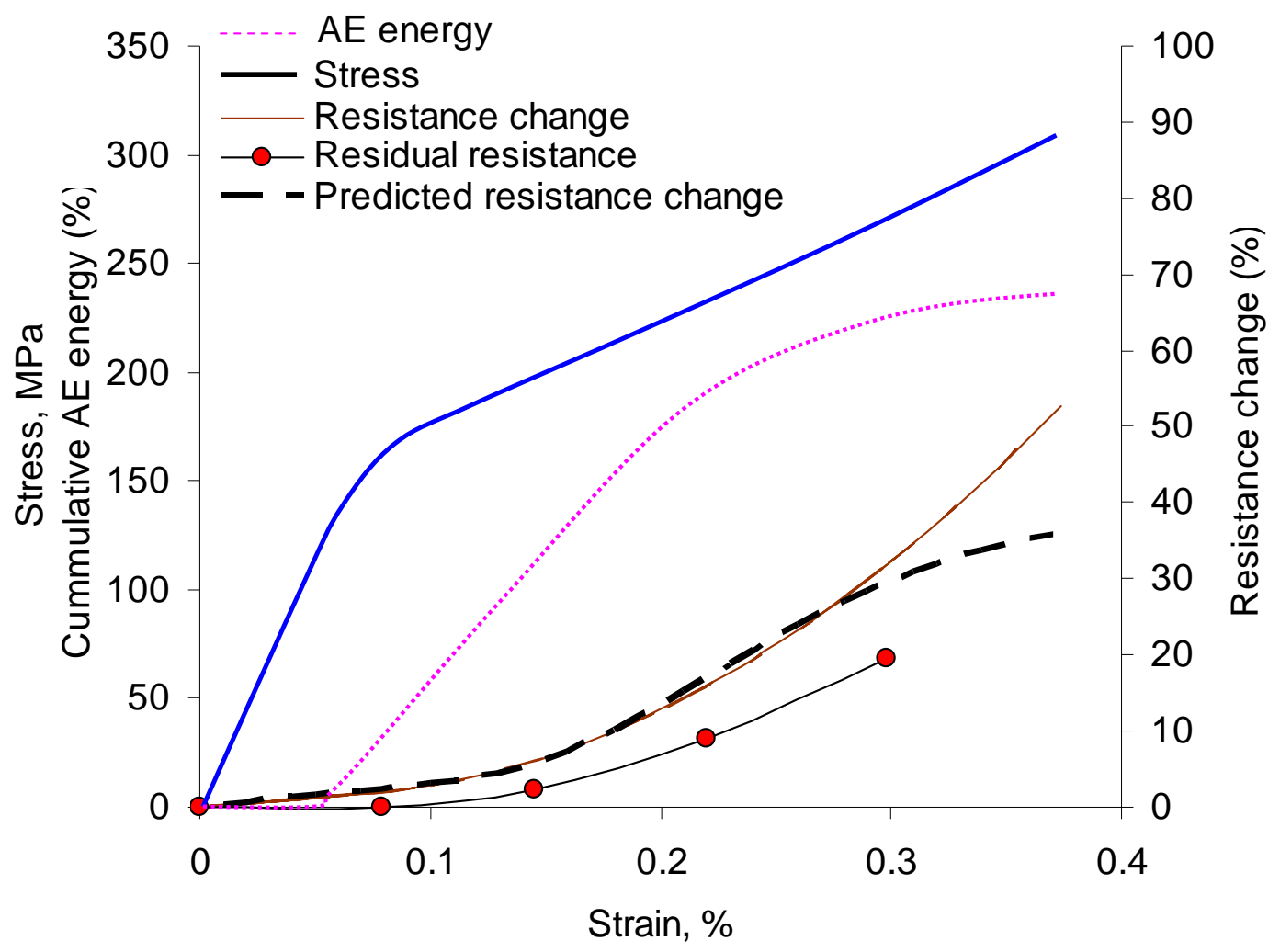

Figure 3. Stress-strain curve, AE energy, maximum, and residual resistance change versus strain for a woven Syl-iBN/CVI composite (only loading parts in load/unload test are shown).

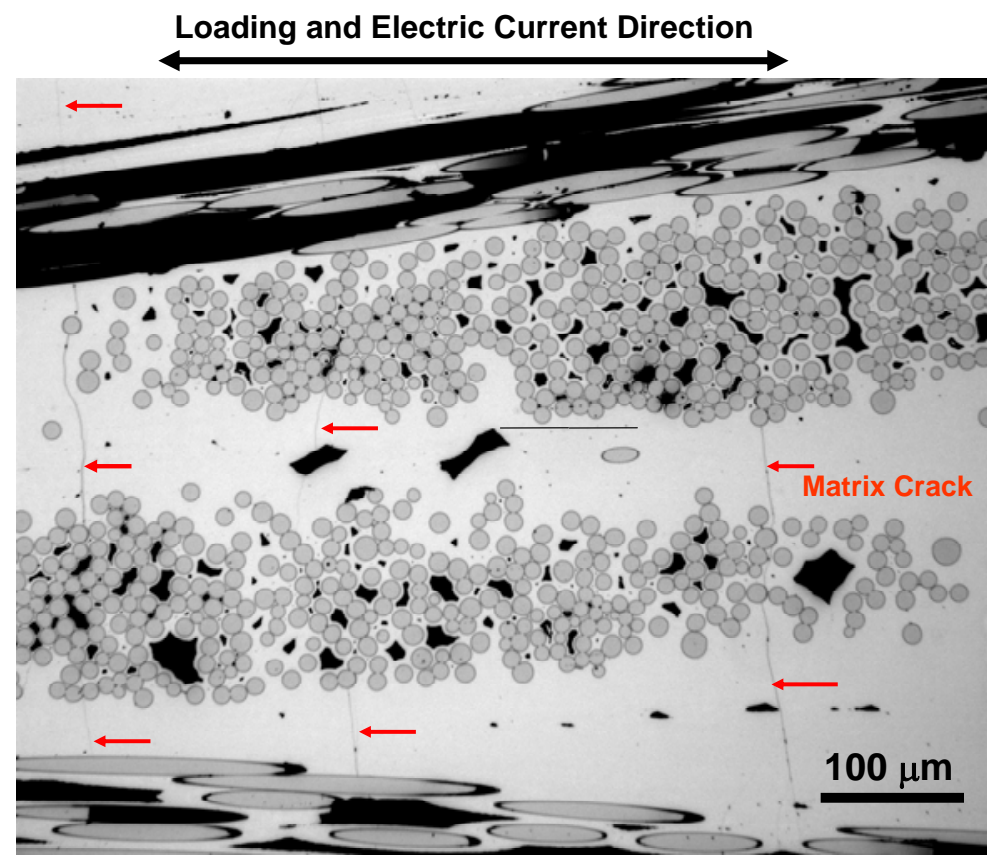

Figure 4. Typical multi ply matrix cracks after load/unload test for Hi-Nicalon/ CVI. 